\title{
Adropin inhibits the phenotypic modulation and proliferation of vascular smooth muscle cells during neointimal hyperplasia by activating the AMPK/ACC signaling pathway
}

\author{
LI WANG $^{1,2}$, LIANG-PING ZHAO ${ }^{1}$, YU-QI CHEN ${ }^{1}$, XIAN-SONG CHANG ${ }^{1}$, HUI XIONG ${ }^{1}$, \\ DAI-MIN ZHANG ${ }^{3}$, WEI-TING XU ${ }^{1}$ and JIAN-CHANG CHEN ${ }^{1}$ \\ ${ }^{1}$ Department of Cardiology, The Second Affiliated Hospital of Soochow University; \\ ${ }^{2}$ Emergency Department, The Second Affiliated Hospital of Soochow University, Suzhou, Jiangsu 215151; \\ ${ }^{3}$ Department of Cardiology, Nanjing First Hospital, Nanjing, Jiangsu 210006, P.R. China
}

Received March 5, 2020; Accepted August 26, 2020

DOI: $10.3892 /$ etm.2021.9992

\begin{abstract}
In-stent restenosis (ISR) remains an inevitable problem for some patients receiving drug-eluting stent (DES) implantation. Intimal hyperplasia is an important biological cause of ISR. It has been previously reported that adropin is a potentially protective factor in cardiovascular disease. Therefore, the present study investigated the function of adropin in inhibiting smooth muscle cell (SMC) phenotype modulation and proliferation, causing intimal hyperplasia. A total of 56 patients who visited the hospital consecutively (25 with ISR and 31 without ISR), who were followed up between April 2016 and March 2019, 1 year following DES, were analyzed to evaluate the association between in-stent neointimal volume and adropin serum levels. Rat aorta smooth muscle cells (RASMCs) were used to determine the effects of adropin on their phenotypic modulation and proliferation using western blot, MTT, PCR and immunofluorescence analyses. Adropin serum levels in the ISR group were significantly lower than those in the non-ISR group. Furthermore, linear regression analysis revealed that only adropin levels were negatively associated with neointimal volume in both groups. The overall adropin levels of the 56 patients and the percentages of neointimal volume revealed a strong negative association. In vitro, adropin suppressed angiotensin II (Ang II)-induced phenotypic modulation in RASMCs by restoring variations of osteopontin and $\alpha$-smooth muscle actin. Furthermore, compared with the Ang II group, adropin markedly decreased the percentage of $\mathrm{G}_{2} / \mathrm{M}$-phase cells. Finally, adropin negatively
\end{abstract}

Correspondence to: Dr Liang-Ping Zhao, Department of Cardiology, The Second Affiliated Hospital of Soochow University, 1055 Sanxiang Road, Suzhou, Jiangsu 215151, P.R. China

E-mail: zhaoliangping1234@aliyun.com

Key words: adropin, neointimal hyperplasia, in-stent restenosis, AMP-activated protein kinase, acetyl-CoA carboxylase, phenotypic modulation, proliferation regulated the phenotypic modulation and proliferation of RASMCs via the AMP-activated protein kinase/acetyl-CoA carboxylase (AMPK/ACC) signaling pathway. In conclusion, an independent, negative association was revealed between adropin and intimal hyperplasia; specifically, adropin inhibited the phenotypic modulation and proliferation of RASMCs by activating the AMPK/ACC signaling pathway. Therefore, adropin may be used as a potential predictor and therapeutic target for intimal hyperplasia and ISR.

\section{Introduction}

Drug-eluting stents (DES) have markedly decreased the incidence and risk of in-stent restenosis (ISR) compared with bare-metal stents, ISR rates after DES implantation have fallen below $10 \%(1,2)$. However, ISR remains a challenging problem for patients receiving DES implantation following percutaneous coronary intervention (PCI), occurring in 3-20\% of the patient population (3). Since there are very few treatment options, numerous studies have focused on the mechanisms, prognosis, predictors and effective treatments of ISR (4-6). It has been revealed that image guidance, such as intra-vascular ultrasound (IVUS) and optical coherence tomography, during stent implantation may be an effective way of decreasing the incidence of ISR; therefore, intracoronary imaging assessments should be performed more frequently to determine the cause of lesions in ISR (7).

Phenotypic modulation and proliferation of vascular smooth muscle cells (VSMCs) are considered as two crucial pathways underlying the pathological process of atherosclerosis (8). SMC transformations from systolic to synthetic phenotypes are regulated by osteopontin (OPN), which promotes the proliferation and migration of SMCs (9). The prevention of SMC migration and proliferation is one of the main approaches to prevent the intimal hyperplasia that causes ISR, which is also a key treatment goal in using DES. Inhibiting mTOR complex 1 (mTORC1) using drugs within a stent, such as sirolimus, has demonstrated marked effects in blocking the development of atherosclerotic plaques; additionally, statins and metformin indirectly inhibit mTORC1 via activating AMP-activated 
protein kinase (AMPK), which slows the development and progression of atherosclerosis (10). Furthermore, it has been previously reported that the activation of AMPK suppresses VSMC proliferation and migration $(11,12)$. Additionally, AMPK downregulates the activity of downstream acetyl-CoA carboxylase (ACC) via phosphorylation, decreasing the synthesis of fatty acids and increasing its oxidation (13). Therefore, the activation of AMPK may serve as the key to inhibit intimal hyperplasia resulting from SMC proliferation and migration.

Adropin was first discovered in 2008 by Kumar et al (14) in the liver and brain of mice, and was considered to represent a novel metabolic protein that modulates glucose and lipid metabolism. Recently, growing evidence has suggested that adropin is a potential regulator of cardiovascular functions and serves a protective role in the development of cardiovascular diseases (15-17). A systematic review indicated that adropin may be a potential serum biomarker for the early diagnosis of heart disease (18). Additionally, it has been previously reported that serum levels of adropin in patients with coronary heart disease were negatively correlated with the Synergy between PCI with Taxus and Cardiac Surgery (SYNTAX) score and the homocysteine level (19). However, the mechanism underlying the ability of adropin to inhibit atherosclerosis is not well understood. Recently, Sato et al (20) described how adropin functioned to prevent atherosclerosis development via suppressing the migration and proliferation of SMCs, which was achieved by downregulating ERK1/2 and Bax, and by upregulating $\mathrm{PI} 3 \mathrm{~K} / \mathrm{Akt} / \mathrm{Bcl} 2$. Currently, little is known about the role of adropin in the migration and proliferation of SMCs in atherosclerosis (20). The present study investigated the association between patients with neointimal hyperplasia and serum adropin levels, and aimed to elucidate the underlying mechanisms of adropin on the phenotypic modulation and proliferation of SMCs, as induced by angiotensin II (Ang II), providing a novel strategy and target for the prevention and treatment of ISR and atherosclerosis.

\section{Materials and methods}

Patients. A total of 56 patients who had been followed up for 1 year after Zotarolimus-eluting stent implantation at The Second Affiliated Hospital of Soochow University (Suzhou, China) were recruited between April 2016 and March 2019. ISR was defined as lumen stenosis $\geq 50 \%$ within the stent (1), as confirmed by coronary angiography. In the present study, all recruited patients had objective and obvious evidence of myocardial ischemia, as determined through electrocardiography findings and typical symptom presentation, including chest pain, sweating, and palpitations. Patients with thrombotic lesions, complete occlusion and recurrent restenosis were excluded from the present study. IVUS was performed according to the degree of restenosis and the willingness of patients and their families. Finally, a total of 56 (age, 58-85 years) patients who were admitted to the hospital consecutively and who underwent IVUS were enrolled in the study. Of these, 25 were defined as having an ISR lesion. All patients provided written informed consent. The present study was approved by the Ethics Committee of The Second Affiliated Hospital of Soochow University.
Blood chemistry. Samples of $2 \mathrm{ml}$ venous blood were collected after overnight fasting. A commercial ELISA kit was used to detect the serum adropin levels, according to the manufacturer's protocol (cat. no. MM-0897R1, JRDUN Biotechnology Co., Ltd.). Serum lipid profiles, including triglyceride, low-density lipoprotein cholesterol and high-density lipoprotein cholesterol levels, were assessed using automated enzymatic procedures (cat. no. 3500, Hitachi, Ltd.).

Quantitative coronary angiography (CAG), IVUS imaging protocol and analysis. CAG was performed following the intravenous injection of heparin and intracoronary injection of sodium nitroprusside. Quantitative CAG was determined via an analysis system (Philips DSA Fd10; Philips Healthcare). The quantitative analysis took place at the end-diastolic phase. An outer diameter guiding catheter filled with iopamidol (a contrast agent) was regarded as the reference standard to detect the reference vessel diameter, minimal lumen diameter and lesion length, and to calculate the diameter stenosis percentage. According to Mehran's classification, patterns of ISR were classified as focal ( $\leq 10 \mathrm{~mm}$ in length) or diffuse (>10 $\mathrm{mm}$ in length) lesions using CAG (21).

Conventional IVUS results were acquired using a Galaxy system (Boston Scientific Corporation) with a $40 \mathrm{MHz}$ mechanically rotating IVUS catheter (Boston Scientific Corporation), with automated transducer pullback at $0.5 \mathrm{~mm} / \mathrm{s}$. The image was acquired at a point that was $\geq 10 \mathrm{~mm}$ (proximally and distally) from the stent. The conventional IVUS measurements were performed according to the standards established by the American College of Cardiology (22). The transducer was operated between the proximal and distal $5-\mathrm{mm}$ reference segments to measure the parameters of the lumen, stent and lesion. In-stent segments were analyzed at a 1-mm axial interval. The cross-sectional area (CSA) of the lumen, the stent CSA, and the neointimal CSA were assessed via two-dimensional conventional IVUS. The neointimal CSA was equal to the stent CSA minus the lumen CSA, which was calculated by the IVUS system. The total volumes of the stent CSA, lumen CSA and neointimal CSA at a 1-mm axial interval constituted conventional three-dimensional IVUS images; associated parameters included stent volume, lumen volume and neointimal volume.

Rat aorta smooth muscle cells (RASMCs) isolation and treatment. Six-week-old male Sprague Dawley (SD) rats (180-200 g) were obtained from the Shanghai SLAC Laboratory Animal Co., Ltd. and housed at $25^{\circ} \mathrm{C}$ under a 12-h light/dark cycle in a specific pathogen-free environment, with free access to food and water. After one week of adaptive feeding, a total of 10 SD rats were used in the present study and were euthanized by intravenous injection of a lethal dose of pentobarbital sodium $(100 \mathrm{mg} / \mathrm{kg})$. After the rat's breathing and heartbeat stop, the rat thoracic aortas were isolated and rinsed three times with PBS. The separated rat aorta was cut into $2-3 \mathrm{~mm}^{2}$ small pieces and digested with collagenase at $37^{\circ} \mathrm{C}$ for $30 \mathrm{~min}$. After centrifugation at $1,000 \mathrm{rpm}\left(1,000 \mathrm{x} \mathrm{g}, 4^{\circ} \mathrm{C}\right)$ for $5 \mathrm{~min}$, the supernatant was discarded, followed by another cycle of PBS washing and centrifugation as aforementioned. The supernatant was discarded, and $2 \mathrm{ml}$ of DMEM containing $10 \%$ FBS (both HyClone; Cytiva) was added to the aortic tissue 
precipitate. After resuspension, the cells were cultured at $37^{\circ} \mathrm{C}$ with $5 \% \mathrm{CO}_{2}$. The cells between passages 6 and 12 were used in the present study. Primary cells extracted from rat arteries contain impurities and a number of endothelial cells (ECs) (23); therefore, primary smooth muscle cells were not directly used in the present study. Previous experience from performing similar techniques indicated that smooth muscle cells have ideal purity and stability after the 6th passage. Furthermore, more passages will cause cell senescence (24), resulting in unstable test results. For example, Jojima et al (25) used SMCs of passages 6-12. Additionally, mycoplasma infection was ruled out by inspecting phase contrast microscopy images. RASMCs were identified via immunocytochemistry (performed as described below in the immunofluorescence assay section) using a monoclonal antibody against $\alpha$-smooth muscle actin ( $\alpha$-SMA; 1:500; cat. no. ab7817; Abcam) to further confirm the purity of the primary cell culture (Fig. S1).

All animal experiments were conducted according to the National Institutes of Health Guidelines for for Care and Use of Laboratory Animals in Biomedical Research (2010) (26). The present study was approved by the Ethics Committee of the Second Affiliated Hospital of Soochow University.

MTT assay. The MTT assay was used to identify the $\mathrm{IC}_{50}$ of adropin, as well as to evaluate the proliferation rate of RASMCs in different groups according to the manufacturer's protocol (Sigma-Aldrich; Merck KGaA). Briefly, the isolated cells were cultured to the logarithmic growth stage. The cell concentration was adjusted to $3 \times 10^{4}$ cells $/ \mathrm{ml}$ and cells were inoculated in 96-well culture plates with $100 \mu \mathrm{l}$ cell suspension per well, and cultured at $37^{\circ} \mathrm{C}$ with $5 \% \mathrm{CO}_{2}$ for $24 \mathrm{~h}$. Subsequently, cells were treated with Ang II (500 ng/ml; cat. no. ab120183; Abcam) and/or compound C ( $1 \mu \mathrm{mol} / \mathrm{l}$; cat. no. ab120843; Abcam) and/or different concentrations of adropin $(0,1,10$, 100 or $1,000 \mathrm{ng} / \mathrm{ml}$; Phoenix Pharmaceuticals, Inc.) at $37^{\circ} \mathrm{C}$ for $48 \mathrm{~h}$. Treated cells were incubated with $15 \mu \mathrm{l}$ MTT at $37^{\circ} \mathrm{C}$ for $4 \mathrm{~h}$. Subsequently, the supernatant was discarded and $150 \mu 1$ DMSO was added. The absorbance was measured at $490 \mathrm{~nm}$ using a microplate spectrophotometer (Thermo Fisher Scientific, Inc.).

Flow cytometry analysis. The cell cycle was analyzed via flow cytometry. RASMCs with a concentration of $10^{5}$ cells $/ \mathrm{ml}$ were seeded into 6 -well culture plates $(3 \mathrm{ml} /$ well) and cultured at $37^{\circ} \mathrm{C}$ with $5 \% \mathrm{CO}_{2}$ for $24 \mathrm{~h}$. Following treatment with Ang II $(500 \mathrm{ng} / \mathrm{ml})$ and/or adropin $(1,000 \mathrm{ng} / \mathrm{ml})$ at $37^{\circ} \mathrm{C}$ for $48 \mathrm{~h}$, the cells underwent $0.25 \%$ trypsinization at room temperature and were centrifuged at $1,200 \mathrm{rpm}(160 \mathrm{x} \mathrm{g})$ at $4^{\circ} \mathrm{C}$ for $3 \mathrm{~min}$. The cells were harvested and washed, then fixed in ice-cold $70 \%$ alcohol at $4^{\circ} \mathrm{C}$ overnight. Subsequently, the samples were incubated with $100 \mu \mathrm{g} / \mathrm{ml}$ RNase A (cat. no. 19101; Qiagen) at room temperature for $30 \mathrm{~min}$ and stained with $50 \mu \mathrm{g} / \mathrm{ml} \mathrm{PI}$ (cat. no. K201; BioVision Inc.) at room temperature for $30 \mathrm{~min}$. The single-cell suspension $(200 \mu 1)$ was analyzed using a FACS Calibur flow cytometer (BD Biosciences), and the results were analyzed using the FlowJo software (version 10.4; FlowJo LLC).

Reverse transcription-quantitative PCR (RT-qPCR). Total RNA from RASMCs was extracted using TRIzol ${ }^{\circledR}$ reagent
(Thermo Fisher Scientific, Inc.). Reverse transcription (incubation at $42^{\circ} \mathrm{C}$ for $60 \mathrm{~min}$ and termination at $70^{\circ} \mathrm{C}$ for $5 \mathrm{~min}$ ) was performed using RevertAid First Strand cDNA Synthesis kit (Thermo Fisher Scientific, Inc.) according to the manufacturer's protocol. The forward and reverse primers (Sangon Biotech Co., Ltd.) used were as follows: GAPDH forward, 5'-ACAGCAACAGGGTGGTGGAC-3' and reverse, 5'-TTT GAGGGTGCAGCGAACTT-3'; $\alpha$-SMA forward, 5'-AGA TTATGTTTGAGACCTTC-3' and reverse, 5'-AGTCCAGCA CAATACCAGTT-3'; and OPN forward, 5'-AGGAGTTTC CCTGTTTCTG-3' and reverse, 5'-TGGTCTTCCCGTTGC TGTC-3'. RT-qPCR was performed using SYBR Green PCR Master Mix (Thermo Fisher Scientific, Inc.) on an Applied Biosystems 7500 Fast Real-Time PCR System (Thermo Fisher Scientific, Inc.). The cycling conditions were as follows: $95^{\circ} \mathrm{C}$ for $15 \mathrm{sec}, 60^{\circ} \mathrm{C}$ for $1 \mathrm{~min}, 95^{\circ} \mathrm{C}$ for $15 \mathrm{sec}$ and $60^{\circ} \mathrm{C}$ for $1 \mathrm{~min}$ for 40 cycles. The $2^{-\Delta \Delta \mathrm{Cq}}$ method (27) was used to calculate the relative gene expression.

Western blot analysis. RASMCs were lysed in RIPA buffer (medium; cat. no. P0013C; Beyotime Institute of Biotechnology) and phenylmethylsulphonyl fluoride $(0.5 \mathrm{mM}$; cat. no. ST505; Beyotime Institute of Biotechnology) to extract the total protein. The concentration of the protein samples was determined using a BCA Protein Assay kit (Biosharp Life Sciences). Next, $12 \mu 1$ protein samples were separated via $8-12 \%$ SDS-PAGE (depends on the molecular weight of target protein) and then transferred onto polyvinylidene fluoride membranes (EMD Millipore). Subsequently, the membranes were blocked using 5\% skimmed milk at room temperature for $1 \mathrm{~h}$, followed by incubation with the following primary antibodies at $4{ }^{\circ} \mathrm{C}$ overnight: Anti-phosphorylated (p)-ACC (1:2,000; cat. no. ab68191), anti-ACC (1:2,000; cat. no. ab109368), anti-p-AMPK (1:1,500; cat. no. ab133448), anti-AMPK (1:2,000; cat. no. ab207442), anti- $\alpha$-SMA (1:1,000; cat. no. ab7817), anti-GAPDH (1:5,000; cat. no. ab8245) and anti-OPN (1:1,000; cat. no. ab8448). All antibodies were purchased from Abcam. Subsequently, the members were incubated with HRP-conjugated secondary antibodies (1:10,000; cat. nos. A16104 and A16072; Thermo Fisher Scientific, Inc.) at room temperature for $1 \mathrm{~h}$. Finally, the protein blots were visualized using an ECL detection system (ChemiScope 5300 Pro; Clinx Science Instruments Co., Ltd.). Quantity One software (version 4.4.6; Bio-Rad Laboratories, Inc.) was used to analyze the density of each band, which was normalized to the loading control GAPDH. All antibodies cross-reacted with their bovine homologs as a positive control.

Immunofluorescence assay. RASMCs were fixed in 4\% paraformaldehyde (cat. no. A0000700; Shanghai Richjoint Chemical Reagent Co., Ltd.) at room temperature for $30 \mathrm{~min}$ and incubated with $0.1 \%$ Triton at room temperature for $15 \mathrm{~min}$. After blocking with $5 \% \mathrm{FBS}$ for $30 \mathrm{~min}$ at $37^{\circ} \mathrm{C}$, the cells were incubated overnight with anti- $\alpha$-SMA (1:500; cat. no. ab7817; Abcam) and anti-OPN (1:500; cat. no. ab8448; Abcam) primary antibodies at $4^{\circ} \mathrm{C}$. Subsequently, cells were incubated with FITC-labeled goat anti-mouse Antibody (1:200; cat. no. 31635; Thermo Fisher Scientific, Inc.) and Cy3-labeled goat anti-rabbit antibody (1:100; cat. no. BA1032; AMSBIO LLC.) for $45 \mathrm{~min}$ at $37^{\circ} \mathrm{C}$. Then, $0.5 \mathrm{ml}$ Hoechst 
33258 staining solution (5 $\mu \mathrm{g} / \mathrm{ml}$; cat. no. C1017; Beyotime Institute of Biotechnology) was added onto the glass slide loading cells sample for $5 \mathrm{~min}$ at room temperature. Finally, the samples were observed under a fluorescence microscope with $\mathrm{x} 40$ magnification (Olympus Corporation). Image analysis was performed using ImageJ software (version 1.8.0; National Institutes of Health).

Statistical analysis. Statistical analysis was performed using SPSS (version 22.0; IBM Corp.). Statistical power calculated using PASS software (Version 11.0.7; NCSS LLC). The data are presented as the mean \pm SEM and percentage. For the analysis of the cell experiments, one-way ANOVA was used, and differences among individual groups were analyzed using the Bonferroni post-hoc test. For the analysis of the clinical data, the categorical variables between the ISR and non-ISR groups were compared using the $\chi^{2}$ test, and the continuous variables using unpaired Student's t-test. Simple linear regression analysis and multiple linear regression analysis were used to assess the association between neointimal volume in ISR and non-ISR groups and different parameters. $\mathrm{P}<0.05$ with statistical power $>0.75$ was considered to indicate a statistically significant difference.

\section{Results}

Baseline patient data. Of the 56 patients enrolled in the present study, ISR was observed in 25 patients (44.6\%). The baseline clinical data of the ISR and non-ISR groups are shown in Table I. There were no significant differences between the two groups in age, sex, body mass index, estimated glomerular filtration rate (eGFR), coronary risk factors liking hypertension, dyslipidemia, diabetes mellitus, smoking, lipid profiles at the initial PCI and second CAG, and medications after stent implanted between the two groups. However, there were significant differences in adropin levels and diseased vessel count between the two groups. In addition, the present sample size of 56 patients did not exhibit sex differences in adropin levels between the two groups (data not shown), although some reports have indicated that adropin levels are higher in males than in females $(28,29)$.

Characteristics of implanted stent and stenosis vessels. The detailed characteristics of the implanted stent and stenosis vessels in the ISR and non-ISR groups are presented in Table II. Few marked differences were observed in terms of diseased vessel location and stent diameter between the two groups. However, the number of stents and total stent length in the ISR group were significantly higher than in the non-ISR group. During the quantitative analysis of the CAG findings, no differences were determined in terms of the reference vessel diameter between the two groups; however, the minimal lumen diameter and lesion length in the ISR group were more aggravated than in the non-ISR group. Furthermore, a significant difference was detected in the restenosis pattern between the two groups, with focal lesions more frequently observed in the ISR group and diffuse lesions more commonly in the non-ISR group.

Stenosis characterization determined via conventional IVUS. Table III shows the cross-sectional characterizations of ISR in the two groups assessed by conventional IVUS. In the two-dimensional analysis of the site of the minimum lumen area, no significant differences in stent area were observed between the two groups. However, the ISR group had a significantly smaller lumen area than the non-ISR group, while the neointimal area of the ISR group was significantly greater than that of the non-ISR group. In the three-dimensional analysis within the stented stenosis segment, patients in the ISR group had significantly greater stent, lumen and neointimal volumes than those in the non-ISR group. Furthermore, the neointimal volume percentage in the ISR group was significantly greater than that in the non-ISR group. These results suggested that neointima in the stent may be a major cause of ISR.

Simple and multiple linear regression analyses of neointimal volume. Tables IV and V show the results of the linear regression analysis between ISR-associated factors and neointimal volume. In terms of the simple linear regression analysis of the ISR and non-ISR groups, the increase in adropin levels had a significant and negative association with neointimal volume; however, the presence of diabetes mellitus was positively associated with neointimal volume in the ISR group $(\mathrm{r}=0.494 ; \mathrm{P}=0.012)$. Although stent number and stent length were notably different between the two groups, they were not significantly associated with neointimal volume in any group. In addition, other factors, such as hypertension, stent number and eGFR (Table IV) had no significant association with neointimal volume. Subsequently, the present study adjusted for confounding factors and screened for factors with an adjusted $\mathrm{R}^{2}$ value $>0.1$. Further multiple linear regression analyses revealed that only adropin levels, rather than dyslipidemia and diabetes, were significantly negatively associated with neointimal volume in both groups (Table V). Subsequently, correlation and linear regression analyses were performed between overall adropin levels for the 56 patients and calculated the neointimal volume percentage; the results revealed a clear negative association between these two variables (Fig. 1). Therefore, there is evidence suggesting that low serum adropin levels are associated with increased neointimal volume, may be a risk factor for ISR.

Cytotoxicity of adropin to RASMCs. To assess cytotoxicity of adropin on RASMCs, the MTT assay was used to detect the optical density (OD) value by treating cells with various concentrations of adropin for 24 or $48 \mathrm{~h}$. The results at $24 \mathrm{~h}$ revealed that the OD values from the RASMCs treated with different concentrations of adropin were similar among each other (Fig. 2A). However, at $48 \mathrm{~h}$, the OD values of the $1,000 \mathrm{ng} / \mathrm{ml}$ and $100 \mathrm{ng} / \mathrm{ml}$ groups were significantly lower than those of the $10 \mathrm{ng} / \mathrm{ml}$ group (Fig. 2B); this indicated that the effect of adropin on RASMCs may be time-dependent. Based on these data the inhibition rates were examined, it showed that adropin inhibited RASMCs in a dose-dependent manner (Fig. 2C). The $\mathrm{IC}_{50}$ value of adropin on RASMCs was $30,850 \mathrm{ng} / \mathrm{ml}$ calculated by SPSS software. The OD results at $24 \mathrm{~h}$ were not significantly different and adropin concentrations $>10 \mathrm{ng} / \mathrm{ml}$ at $48 \mathrm{~h}$ are toxic to RASMCs. Also, $10 \mathrm{ng} / \mathrm{ml}$ is closed to physiological level. Therefore, cells that were treated for $48 \mathrm{~h}$ with $10 \mathrm{ng} / \mathrm{ml}$ adropin were selected for subsequent experiments. 
Table I. Baseline characteristics of patients with ISR $(n=25)$ and without ISR $(n=31)$.

\begin{tabular}{|c|c|c|c|}
\hline Characteristic & ISR & non-ISR & P-value \\
\hline Age, years & $59.28 \pm 10.03$ & $61.35 \pm 8.85$ & 0.423 \\
\hline Female/male & $7 / 18$ & $10 / 21$ & 0.730 \\
\hline Body mass index, $\mathrm{kg} / \mathrm{m}^{2}$ & $23.76 \pm 1.75$ & $23.95 \pm 2.04$ & 0.721 \\
\hline eGFR $\left(\mathrm{ml} / \mathrm{min} / 1.73 \mathrm{~m}^{2}\right)$ & $69.54 \pm 23.09$ & $73.06 \pm 25.60$ & 0.594 \\
\hline Hypertension & $17(68.00)$ & $22(70.97)$ & 0.810 \\
\hline Dyslipidemia & $20(80.00)$ & $16(51.61)$ & 0.243 \\
\hline Diabetes mellitus & $11(44.00)$ & $9(29.03)$ & 0.245 \\
\hline Smoking & $12(48.00)$ & $8(25.81)$ & 0.085 \\
\hline \multicolumn{4}{|l|}{ Lipid profiles, at initial PCI } \\
\hline HDL-C, mmol/1 & $1.27 \pm 0.32$ & $1.35 \pm 0.49$ & 0.493 \\
\hline LDL-C, mmol/1 & $3.38 \pm 0.73$ & $3.17 \pm 0.77$ & 0.320 \\
\hline Triglyceride, mmol/l & $1.94 \pm 1.14$ & $1.82 \pm 0.97$ & 0.683 \\
\hline \multicolumn{4}{|l|}{ Lipid profiles, at second $\mathrm{CAG}$} \\
\hline HDL-C, mmol/1 & $1.37 \pm 0.27$ & $1.45 \pm 0.37$ & 0.406 \\
\hline LDL-C, mmol/l & $2.96 \pm 0.62$ & $2.68 \pm 0.63$ & 0.110 \\
\hline Triglyceride, mmol/l & $1.74 \pm 1.02$ & $1.63 \pm 0.79$ & 0.644 \\
\hline Adropin, ng/ml & $2.74 \pm 0.55$ & $3.59 \pm 0.65$ & $<0.001$ \\
\hline Diseased vessel count, $\mathrm{n}$ & $1.36 \pm 0.49$ & $1.10 \pm 0.30$ & $0.017^{\mathrm{a}}$ \\
\hline \multicolumn{4}{|c|}{ Medications after stent implanted } \\
\hline Aspirin & $25(100.00)$ & $31(100.00)$ & 1.000 \\
\hline Clopidogrel & $22(88.00)$ & 30 (96.77) & 0.456 \\
\hline Statin & $20(80.00)$ & $29(93.55)$ & 0.264 \\
\hline ACEI/ARB & $14(56.00)$ & $18(58.06)$ & 0.877 \\
\hline$\beta$-blocker & $10(40.00)$ & $14(45.16)$ & 0.698 \\
\hline Calcium channel blockers & $8(32.00)$ & $11(35.48)$ & 0.784 \\
\hline Insulin treatment & $3(12.00)$ & $2(6.45)$ & 0.801 \\
\hline
\end{tabular}

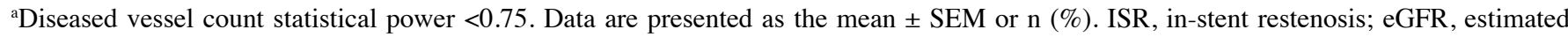
glomerular filtration rate. PCI, percutaneous coronary intervention; ACEI, angiotensin-converting enzyme inhibitor; ARB, angiotensin receptor blocker; HDL-C, high-density lipoprotein cholesterol; LDL-C, low-density lipoprotein cholesterol.



Figure 1. Pearson correlation and linear regression analysis between adropin levels and percentage of neointimal volume in 56 patients. ISR, in-stent restenosis.

Adropin suppresses Ang II-induced phenotypic modulation of RASMCs. SMCs convert its contractile phenotypes into synthetic phenotypes, which is accompanied by significantly decreased $\alpha$-SMA expression and markedly increased levels of OPN (30). To verify the effects of adropin on the phenotype of RASMCs, changes in $\alpha$-SMA and OPN expression in RASMCs treated with Ang II were detected. The results from the RT-qPCR, western blotting and quantitative fluorescence analyses revealed that Ang II induced significant OPN upregulation and significant $\alpha$-SMA downregulation compared with untreated cells; however, adropin reversed this phenotypic change (Fig. 3A, B, Ca, Cb and D). Therefore, it was speculated that adropin may slow down the phenotypic modulation of RASMCs induced by Ang II. In order to investigate the effects of adropin on AMPK and ACC, their expression and phosphorylation levels were assessed. The western blotting results indicated that adropin recovered the activities of ACC and AMPK by decreasing the expression levels of p-ACC and increasing those of p-AMPK, compared with the Ang II group (Fig. 3B, Cc and Cd). AMPK is a key factor in inhibiting intimal hyperplasia; consequently, adropin may contribute to decreasing neointima through the activation of AMPK.

Adropin inhibits Ang II-induced proliferation of RASMCs. It was demonstrated that RASMCs treated with Ang II presented a significantly increased proliferation compared with untreated cells; however, adropin weakened the effect of Ang II on RASMC proliferation (Fig. 4A). Furthermore, it was revealed that adropin 
Table II. Characteristics of patients with ISR ( $n=25)$ and without ISR $(n=31)$.

\begin{tabular}{lcrr}
\hline Characteristic & ISR & non-ISR & P-value \\
\hline Location & & & 0.678 \\
$\quad$ Left anterior descending artery & $11(44.00)$ & $12(38.71)$ & \\
Left circumflex artery & $4(16.00)$ & $5(16.13)$ & \\
Right coronary artery & $10(40.00)$ & $14(45.16)$ & 0.291 \\
Stent diameter, mm & $2.92 \pm 0.52$ & $3.06 \pm 0.47$ & 0.014 \\
Total stent length, mm & $36.96 \pm 15.87$ & $27.65 \pm 11.40$ & 0.011 \\
Number of stents & $1.40 \pm 0.50$ & $1.10 \pm 0.30$ & 0.532 \\
Quantitative coronary angiography & & & $<0.001$ \\
Reference vessel diameter, mm & $2.85 \pm 0.52$ & $2.94 \pm 0.48$ & $<0.001$ \\
Minimal lumen diameter, mm & $1.17 \pm 0.24$ & $1.98 \pm 0.41$ & $<0.001$ \\
\% diameter stenosis & $59.76 \pm 3.79$ & $35.06 \pm 8.38$ & 0.001 \\
Lesion length, mm & $9.38 \pm 2.82$ & $3.55 \pm 1.26$ & \\
Restenosis pattern & & & \\
Focal & $16(64.00)$ & $25(19.35)$ & \\
Diffuse & $9(36.00)$ & &
\end{tabular}

Data are presented as the mean \pm SEM or $\mathrm{n}(\%)$. ISR, in-stent restenosis.
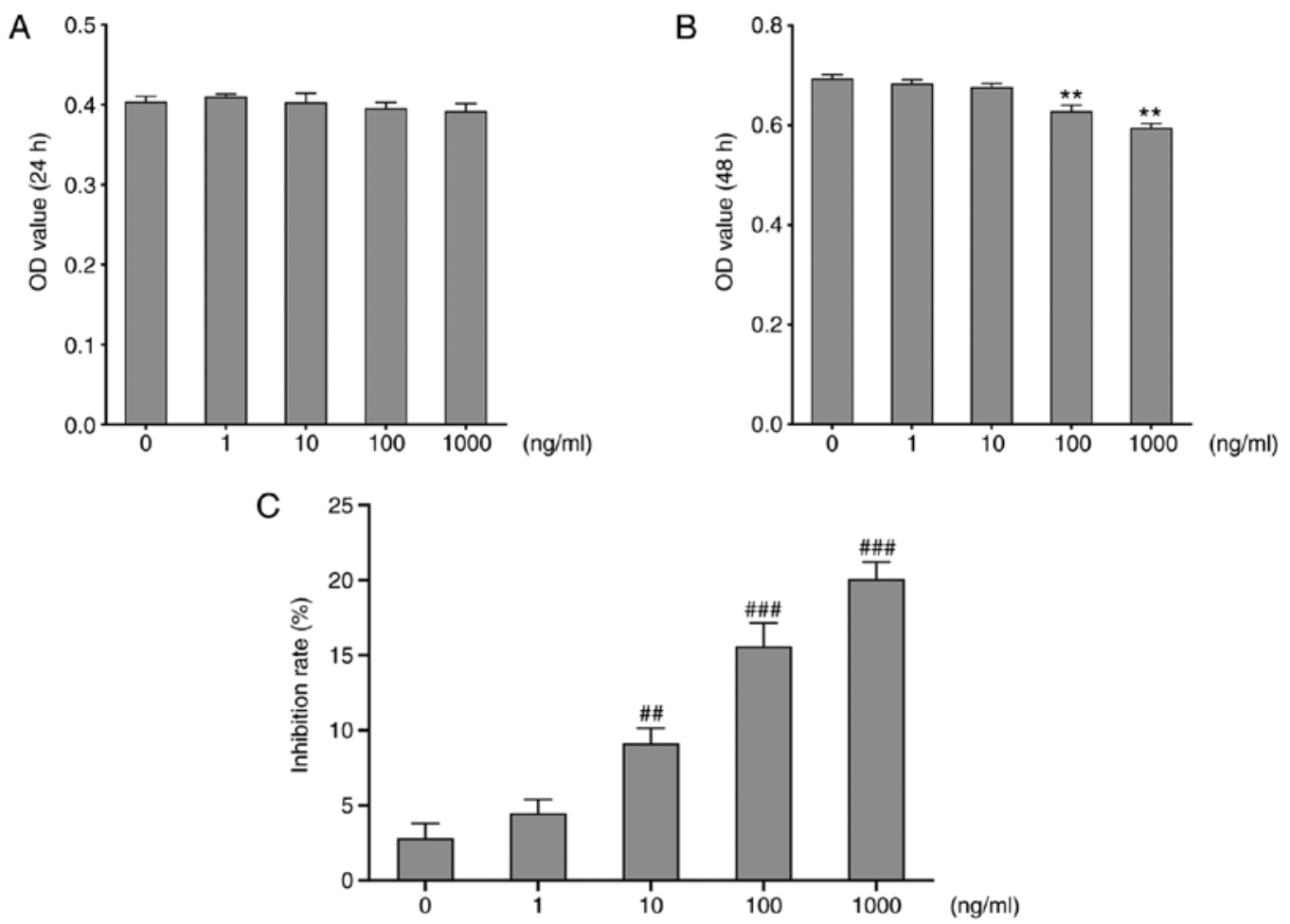

Figure 2. Cytotoxicity of different concentrations of adropin on rat aorta smooth muscle cells. OD values after treatment for (A) 24 and (B) 48 h. (C) Inhibition rates of various concentrations of adropin. Data are presented as the mean $\pm \mathrm{SEM}(\mathrm{n}=3) .{ }^{\# \#} \mathrm{P}<0.01,{ }^{\# \#} \mathrm{P}<0.001 \mathrm{vs}$. $0 \mathrm{ng} / \mathrm{ml}$. ${ }^{* *} \mathrm{P}<0.01 \mathrm{vs}$. $10 \mathrm{ng} / \mathrm{ml}$. OD, optical density.

significantly decreased the amount of cells in the $G_{2} / M$ phase compared with that in the Ang II group (Fig. 4B and C).

Adropin negatively regulates the phenotypic modulation and proliferation of RASMCs via the AMPK/ACC signaling pathway. It has been previously reported that the AMPK signaling pathway influences the cellular phenotype and proliferation of VSMCs $(31,32)$. The present study demonstrated that adropin affected the AMPK/ACC signaling pathway and suppressed the Ang II-induced phenotypic modulation of RASMCs. Therefore, it was speculated that adropin may regulate the phenotypic modulation and 
Table III. Conventional intravascular ultrasound characterization of ISR-neointimal hyperplasia in patients with ISR ( $\mathrm{n}=25$ ) and without ISR $(n=31)$.

\begin{tabular}{|c|c|c|c|}
\hline Analysis & ISR & non-ISR & P-value \\
\hline \multicolumn{4}{|c|}{ Two-dimensional analysis (minimum lumen area) } \\
\hline Stent area, $\mathrm{mm}^{2}$ & $6.76 \pm 2.56$ & $7.39 \pm 2.43$ & 0.341 \\
\hline Lumen area, $\mathrm{mm}^{2}$ & $1.13 \pm 0.47$ & $3.15 \pm 1.45$ & $<0.001$ \\
\hline Neointimal area, $\mathrm{mm}^{2}$ & $5.62 \pm 2.15$ & $4.26 \pm 1.60$ & 0.008 \\
\hline \multicolumn{4}{|c|}{ Three-dimensional analysis within stented segment } \\
\hline Stent volume, $\mathrm{mm}^{3}$ & $63.17 \pm 31.00$ & $26.20 \pm 11.34$ & $<0.001$ \\
\hline Lumen volume, $\mathrm{mm}^{3}$ & $24.33 \pm 10.46$ & $17.67 \pm 8.36$ & 0.010 \\
\hline Neointimal volume, $\mathrm{mm}^{3}$ & $38.84 \pm 23.09$ & $8.53 \pm 4.13$ & $<0.001$ \\
\hline Neointimal volume, $\%$ a & $59.33 \pm 11.04$ & $31.82 \pm 8.79$ & $<0.001$ \\
\hline
\end{tabular}

${ }^{a}$ Calculated as the neointimal volume divided by the lumen volume $\mathrm{x} 100$. Data are presented as the mean \pm SEM. ISR, in-stent restenosis.
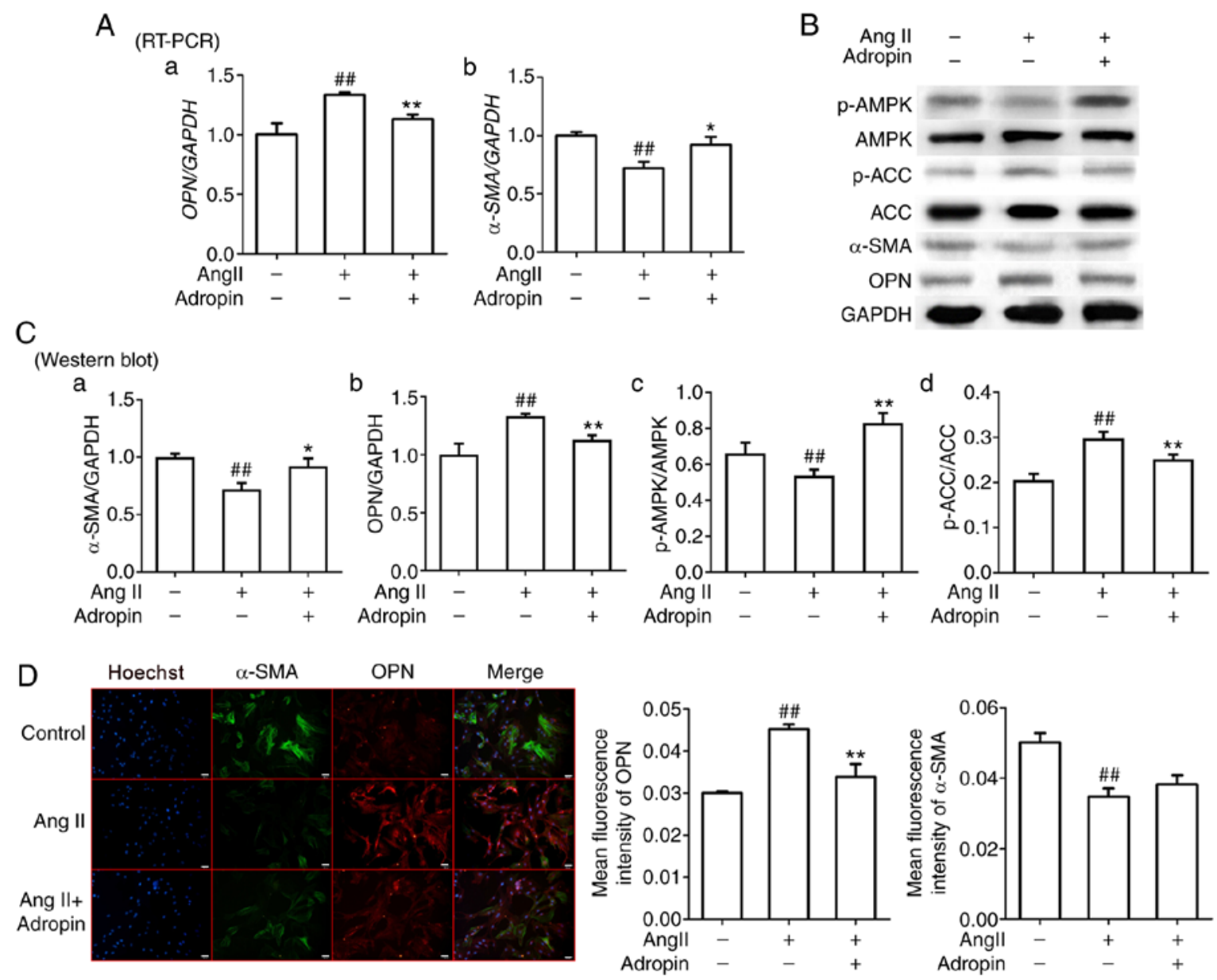

Figure 3. Effects of adropin on the phenotypic modulation of rat aorta smooth muscle cells and the AMPK/ACC signaling pathway. (A) RT PCR results of $\alpha$ SMA (Aa) and OPN (Ab) expression. (B) Western blot results and (C) quantification of protein expression levels of $\alpha$ SMA (Ca), OPN (Cb), p AMPK/AMPK $(\mathrm{Cc})$ and $\mathrm{p}$ ACC/ACC (Cd). (D) Representative immunofluorescence images of $\alpha$ SMA and OPN expression. Scale bar, $20 \mu \mathrm{m}$. Data are presented as the mean \pm SEM ( $n=3)$. "P<0.05, ${ }^{* *} \mathrm{P}<0.01$ vs. Ang II. ${ }^{\# \#} \mathrm{P}<0.01$ vs. control. RT-PCR, reverse transcription PCR; $\alpha$-SMA, $\alpha$-smooth muscle actin; OPN, osteopontin; $p$, phosphorylated; AMPK, AMP-activated protein kinase; ACC, acetyl-CoA carboxylase; Ang II, angiotensin II.

proliferation of RASMCs through the APMK/ACC signaling pathway. Compound C, an AMPK-specific inhibitor, was used to verify the aforementioned hypothesis. Firstly, the western blotting results revealed that, compared with the
Ang II + compound C group, adropin significantly increased the ratio of $\mathrm{p}$-AMPK/AMPK and significantly decreased the ratio of $\mathrm{p}$-ACC/ACC in the Ang $\mathrm{II}+$ compound $\mathrm{C}+$ adropin group, suggesting that ACC activity was retained by adropin 
Table IV. Simple linear regression analysis.

Neointimal volume

\begin{tabular}{cccccc}
\hline \multicolumn{2}{c}{ ISR group } & & & \multicolumn{2}{c}{ non-ISR group } \\
\cline { 5 - 6 } adjusted $\mathrm{R}^{2}$ & P-value & & $\mathrm{r}$ & adjusted $\mathrm{R}^{2}$ & P-value \\
\hline 0.364 & 0.001 & -0.525 & 0.250 & 0.002 \\
0.211 & 0.012 & 0.136 & -0.015 & 0.465 \\
0.103 & 0.065 & 0.008 & -0.034 & 0.966 \\
0.098 & 0.070 & 0.182 & 0.000 & 0.326 \\
0.071 & 0.106 & 0.063 & -0.030 & 0.735 \\
0.056 & 0.134 & 0.260 & 0.036 & 0.157 \\
0.033 & 0.191 & 0.196 & 0.005 & 0.290 \\
0.025 & 0.216 & 0.104 & -0.023 & 0.576 \\
0.024 & 0.222 & 0.315 & 0.068 & 0.084 \\
0.011 & 0.271 & 0.143 & -0.013 & 0.444 \\
-0.007 & 0.371 & 0.057 & -0.031 & 0.760 \\
-0.008 & 0.378 & 0.072 & -0.029 & 0.700 \\
-0.013 & 0.415 & 0.091 & -0.026 & 0.625 \\
-0.028 & 0.207 & 0.033 & -0.033 & 0.860 \\
-0.033 & 0.641 & 0.176 & -0.003 & 0.345 \\
-0.041 & 0.829 & 0.044 & -0.032 & 0.814 \\
-0.042 & 0.875 & 0.291 & 0.053 & 0.112 \\
\hline
\end{tabular}

ISR, in-stent restenosis; ACEI, angiotensin-converting enzyme inhibitor; ARB, angiotensin receptor blocker; eGFR, estimated glomerular filtration rate; $\mathrm{CCB}$, calcium channel blocker.
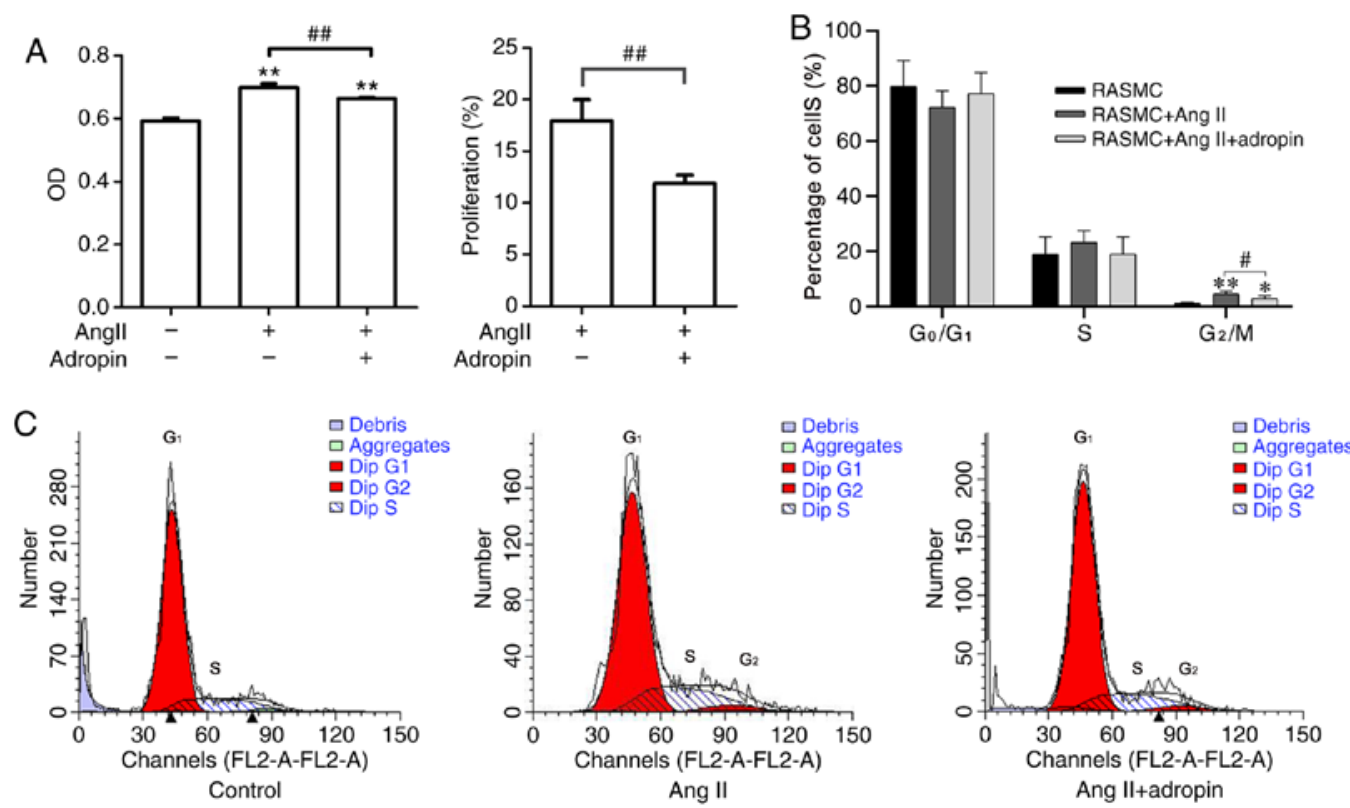

Figure 4. Effect of adropin on the proliferation of RASMCs and cell cycle progression. (A) Adropin decreased the proliferation of RASMCs induced by Ang II evaluated via MTT assay. (B and C) Adropin decreased the ratio of cells in $\mathrm{G}_{2} / \mathrm{M}$ phase detected via flow cytometry. Data are presented as the mean \pm SEM $(\mathrm{n}=3) .{ }^{*} \mathrm{P}<0.05,{ }^{* *} \mathrm{P}<0.01$ vs. control. ${ }^{\#} \mathrm{P}<0.05,{ }^{\# \#} \mathrm{P}<0.01$. RASMCs, rat aorta smooth muscle cells; Ang II, angiotensin II.

(Fig. 5A and C). Secondly, the RT-qPCR and western blotting results indicated that the expression levels of OPN and $\alpha$-SMA between the Ang II and Ang II + compound C groups were not significantly different. Following the addition of adropin to the Ang II + compound C group, the increase in OPN and decrease in $\alpha$-SMA were reversed, compared with no adropin 
Table V. Multiple linear regression analysis for confounding factors.

Neointimal volume $\left(\mathrm{mm}^{3}\right)$

\begin{tabular}{|c|c|c|c|c|}
\hline \multirow[b]{2}{*}{ Parameter } & \multicolumn{2}{|c|}{ ISR group } & \multicolumn{2}{|c|}{ non-ISR group } \\
\hline & $\beta$ coefficient & P-value & $\beta$ coefficient & P-value \\
\hline Adropin & -0.509 & 0.022 & -0.526 & 0.003 \\
\hline Dyslipidemia & 0.140 & 0.945 & 0.033 & 0.853 \\
\hline Diabetes & -0.256 & 0.198 & -0.158 & 0.370 \\
\hline
\end{tabular}

ISR, in-stent restenosis.
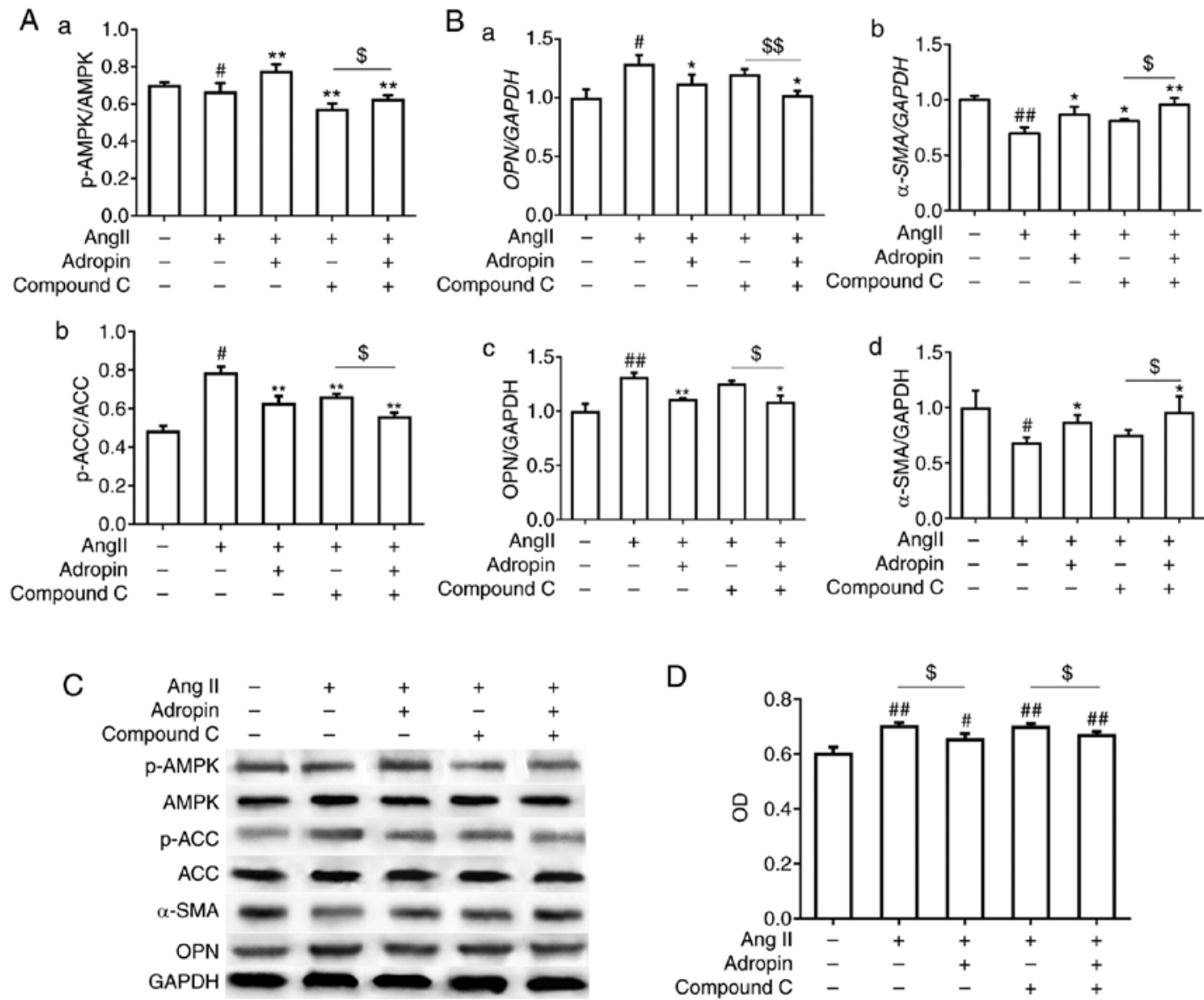

Figure 5. Adropin regulates the phenotypic modulation and proliferation of RASMCs through the AMPK/ACC signaling pathway. (A) Western blot results of the variations in (Aa) p-AMPK/AMPK and (Ab) p-ACC/ACC. (Ba and Bb) reverse transcription PCR and (Bc and Bd) western blotting results for OPN and $\alpha$-SMA expression. (C) Protein bands of p-ACC/ACC, p-AMPK/AMPK, OPN and $\alpha$-SMA via western blotting. (D) Proliferation of RASMCs detected

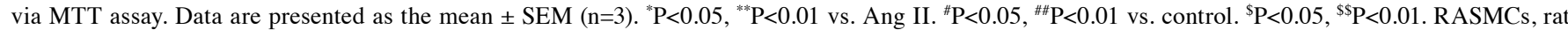
aorta smooth muscle cells; $\alpha$-SMA, $\alpha$-smooth muscle actin; OPN, osteopontin; p, phosphorylated; AMPK, AMP-activated protein kinase; ACC, acetyl-CoA carboxylase; Ang II, angiotensin II.

(Fig. 5B and C). Furthermore, the MTT assay revealed that adropin significantly decreased the RASMC proliferation induced by Ang II, and presented a similar anti-proliferative effect with the addition of compound C on RASMCs (Fig. 5D). Therefore, the present results suggested that adropin inhibited the phenotypic modulation and proliferation of RASMCs through the AMPK/ACC signaling pathway.

\section{Discussion}

The present study identified adropin as a novel regulator of VSMC function, revealing that serum adropin levels in patients with ISR were negatively associated with neointimal volume. To the best of our knowledge, the current study demonstrated for the first time in vitro that adropin potently inhibited the 
Ang II-induced phenotypic modulation and proliferation of RASMCs by regulating the AMPK/ACC signaling pathway. The aforementioned findings indicated that adropin may be a potentially important target for the treatment and prediction of neointimal hyperplasia.

The incidence of ISR in patients after PCI has remained relatively constant $(\sim 10 \%)$ despite the technical progress in DES (7). The causes of ISR are complex, and can be biological, mechanical and technical (1). Technical causes include stent fracture or stent underexpansion, while neointimal proliferation and late neoatherosclerosis constitute the primary biological causes (7). Although using high-pressure balloons decreases the occurrence of stent underexpansion, and a novel stent replaces the restenotic one (33), there are few medical therapies available to cope with neointimal proliferation. Oral administration of sirolimus, corticosteroids or the local delivery of paclitaxel exhibited a limited effect in suppressing intimal hyperplasia (34). A previous study investigated the local delivery of nanoparticles containing VEGF cDNA to a target artery in an animal model to inhibit intimal hyperplasia (35); however, this novel therapy requires further investigation and clinical trials to determine its efficacy and safety. Patients with complications such as diabetes, chronic kidney disease and bifurcation lesions are susceptible to ISR (36). In the present study, differences in coronary risk factors, such as hypertension, dyslipidemia, diabetes mellitus, and smoking and the lipid profiles between the ISR and non-ISR groups were not significant. It was speculated that this may be due to it being a retrospective study with a small sample size and only featuring a 1-year follow-up time. Numerous studies reported that the most common pattern of ISR was focal (37-39), which is in accordance with the current data. However, the cause of the focal pattern observed in the present study has not been completely elucidated. Although the total stent length in the ISR group was significantly greater than that of the non-ISR group, the total stent length and number of stents were not risk factors for ISR according to the present regression analysis. A previous study reported that longer stents were a predictive factor for DES restenosis; however, the total stent length and number of stents were not risk factors for ISR (1). Furthermore, Zhao et al (40) reported that stent length was not a predictor of ISR in patients, as determined through univariate logistic regression analysis. Therefore, it is difficult to precisely evaluate the influence of the total stent length and stent number in ISR in the present study. Additionally, DES fracture has been associated with higher major adverse cardiovascular events, stent thrombosis and ISR (41,42). Fracture following DES implantation, as seen in a rabbit model, focally accelerated intimal hyperplasia; however, the anti-proliferative drugs were under a designed effective release period (43). Therefore, it is especially important to identify other methods to inhibit intimal hyperplasia of ISR.

Neoatherosclerosis and inflammation underlying the formation of intimal hyperplasia cannot be addressed through stent implantation (1); therefore, ISR will inevitably occur to some extent. The present results indicated that the levels of adropin in the ISR group were significantly lower than those in the non-ISR group, and that the adropin levels in both groups were negatively associated with neointimal volume. Therefore, it was hypothesized that adropin may relieve the progression of intimal hyperplasia. Subsequent in vitro experiments indicated that adropin inhibited the phenotypic modulation and proliferation of
RASMCs, and it is well known that the proliferation and migration of VSMCs are essential processes of atherosclerosis (44). Adropin is a protein associated with energy homeostasis and, to the best of our knowledge, only an extremely small number of studies have investigated the association between adropin, proliferation and migration in VSMCs. It has been recently reported that adropin inhibits TNFa-induced THP1 monocyte adhesion to the vascular endothelial cells; additionally, adropin restrains the migration and proliferation of SMCs through the downregulation of ERK1/2 and Bax, and the upregulation of PI3K/Akt/Bcl2 (20). Furthermore, it has been demonstrated that adropin has a potential protective role on endothelial cells through the VEGFR2/PI3K signaling pathway (45). The aforementioned functions of adropin may have contributed to the anti-atherosclerosis effects. The present study provided evidence to confirm that adropin suppressed the phenotypic modulation and proliferation of VSMCs, which may reduce intimal hyperplasia.

In contrast to the PI3K/Akt signaling pathway, which is a well-studied signaling pathway involving VSMC proliferation, the present study revealed that adropin significantly attenuated the proliferative characteristics of the Ang II-induced VSMCs model via the AMPK/ACC signaling pathway. Generally, AMPK is regarded as a molecule that promotes ATP synthesis and restores energy homeostasis in the cell (46). However, studies have indicated that AMPK has notable effects on cellular growth arrest $(47,48)$. The cell-cycle analysis performed in the current study revealed that adropin induced $G_{0} / G_{1}$ arrest and prevented the cell cycle from entering the $S$ phase. Previous studies have demonstrated that AMPK inhibits SMC proliferation (49,50), as well as migration (51), and the deletion of AMPK exacerbates neointimal hyperplasia (52). In addition, ACC, as one of the downstream targets of AMPK, transmits signals from AMPK to p53 and p21, which induces cell-cycle arrest (53). The present study revealed that the phosphorylation of AMPK inhibited ACC activity by increasing the ratio of p-ACC/ACC, leading to weakened proliferation and migration in VSMCs. Although the current study revealed that adropin may be an upstream factor that activates AMPK, to the best of our knowledge there are currently no studies reporting the effect of adropin on AMPK in VSMCs. Therefore, the present study reported, for the first time, that adropin may activate AMPK to inhibit the proliferation and migration of VSMCs.

The AMPK signaling pathway is a well-known energy metabolism pathway, especially involved in the promotion of fatty acid $\beta$-oxidative metabolism (54). Adropin promotes the oxidation of fatty acids and lipoproteins $(55,56)$, and in the present study, it inhibited neointimal hyperplasia via activating the AMPK/ACC signaling pathway. Although the AMPK/ACC signaling pathway is crucial in the oxidation of fatty acids (57), the effect of adropin on substrate oxidation preferences, such as fatty acids or glucose, remains unclear. Gao et al (58) reported that adropin promotes carbohydrate oxidation over fat oxidation in skeletal muscle. Additionally, adropin increases the inhibitory effect of insulin on cardiac fatty acid oxidation, accompanied by a strong stimulation of glucose oxidation (16). However, a recent study suggested that, in contrast to skeletal muscle, metabolic effects of adropin on cardiac cells may occur primarily through the regulation of glucose utilization, rather than the inhibition of fatty acid metabolism, and that adropin did not differentially 
phosphorylate AMPK and ACC (59). Therefore, although the present study revealed that adropin promoted the activation of the AMPK signaling pathway, it is difficult to directly attribute the effect of adropin on ISR inhibition to the function of adropin that promotes fatty acid metabolism, since the effects of adropin on fatty acid metabolism in cardiovascular disease remain unclear. Carnitine O-palmitoyl transferase 1 (CPT1A) and peroxisomal acyl-coenzyme A oxidase 1 (ACOX1) participate in an important step of the mitochondrial uptake of long-chain fatty acids and their subsequent $\beta$-oxidation in the mitochondrion, and they serve essential roles in triglyceride metabolism (60-62). Therefore, CPT1a and ACOX1 may be ideal markers for detecting the function of adropin on fatty acid $\beta$-oxidative metabolism. Future studies should investigate whether adropin may decrease ISR occurrence via promoting fatty acid metabolism.

The current study presents some limitations. It has been previously reported that adropin is a risk factor for the development of cardiovascular disease $(19,62)$, which is in accordance with the conclusions of the present study. Although statistical power was achieved to ensure that the results were credible, the current retrospective study only consisted of 56 patients. The small number of patients with ISR may render the linear regression results unstable. In future studies, the sample size should be increased to investigate the exact association between adropin and neointima. Furthermore, there was no marked difference between the two $\beta$-coefficient values of adropin in the multiple linear regression analysis of the ISR and non-ISR groups; therefore, adropin seems to have predictive significance in both groups. Additionally, the median time from DES implantation to ISR occurrence is 14 months (37), but in the present study, the prognosis of the 56 patients was only followed up for 1 year; therefore, the efficacy of adropin over a longer period of time in intimal hyperplasia could not be determined.

Overall, independent, negative associations were identified between adropin levels and intimal hyperplasia, and adropin inhibited the phenotypic modulation and proliferation of VSMCs by activating the AMPK/ACC signaling pathway. Therefore, the present results indicated that adropin may represent a potentially novel target for the treatment and prediction of intimal hyperplasia.

\section{Acknowledgements}

Not applicable.

\section{Funding}

The present study was funded by the Suzhou Science and Technology Development Program Guidance Project Fund (grant no. SYSD2013093), the Youth Natural Science Fund of Soochow University (grant no. SDY2013A32), Xinxin Heart (SIP) Foundation (2019-CCA-ACCESS-058), and the Research Fund of the Second Affiliated Hospital of Soochow University (grant no. SDFEYGJ1405).

\section{Availability of data and materials}

The datasets used and/or analyzed during the current study are available from the corresponding author on reasonable request.

\section{Authors' contributions}

LPZ designed the study and revised the manuscript. LW, YQC, XSC and HX assisted with data acquisition and interpretation. DMZ, WTX and JCC performed the statistical analysis and drafted the manuscript. All authors read and approved the final manuscript.

\section{Ethics approval and consent to participate}

The present study was approved by the Ethics Committee of The Second Affiliated Hospital of Soochow University. (Suzhou, China). Written informed consent was obtained from the patients or their guardians. All animal experiments were conducted according to the National Institutes of Health Guidelines for Animal Care, eighth edition, revised 2011 (25).

\section{Patient consent for publication}

Not applicable.

\section{Competing interests}

The authors declare that they have no competing interests.

\section{References}

1. Dangas GD, Claessen BE, Caixeta A, Sanidas EA, Mintz GS and Mehran R: In-stent restenosis in the drug-eluting stent era. J Am Coll Cardiol 56: 1897-1907, 2010.

2. Babapulle MN, Joseph L, Bélisle P, Brophy JM and Eisenberg MJ: A hierarchical bayesian meta-analysis of randomised clinical trials of drug-eluting stents. Lancet 364: 583-591, 2004.

3. Solinas E, Dangas G, Kirtane AJ, Lansky AJ, Franklin-Bond T, Boland P, Syros G, Kim YH, Gupta A, Mintz G, et al: Angiographic patterns of drug-eluting stent restenosis and one-year outcomes after treatment with repeated percutaneous coronary intervention. Am J Cardiol 102: 311-315, 2008.

4. Lu WD, Huang CW, Li YH and Chen JY: Multiple mechanisms in 1 in-stent restenosis assessed by optical coherence tomography. JACC Cardiovasc Interv 10: 2340-2341, 2017.

5. Kim WJ, Yoon SE, Kang SM, Jo U, Park HW, Cho YR, Park GM, Lee JY, Park DW, Kang SJ, et al: Long term prognosis of in-stent restenosis after drug-eluting stent implantation and predictors of recurrent restenosis: Data from the ASAN DES-ISR registry. Am J Cardiol 111 (7 Suppl): 27B, 2013.

6. Farb A, Sangiorgi G, Carter AJ, Walley VM, Edwards WD, Schwartz RS and Virmani R: Pathology of acute and chronic coronary stenting in humans. Circulation 99: 44-52, 1999.

7. Shlofmitz E, Iantorno $M$ and Waksman R: Restenosis of drug-eluting stents: A new classification system based on disease mechanism to guide treatment and state-of-the-art review. Circ Cardiovasc Interv 12: e007023, 2019.

8. Ross R: Atherosclerosis-an inflammatory disease. N Engl J Med 340: 115-126, 1999.

9. Isoda K, Nishikawa K, Kamezawa Y, Yoshida M, Kusuhara M, Moroi M, Tada N and Ohsuzu F: Osteopontin plays an important role in the development of medial thickening and neointimal formation. Circ Res 91: 77-82, 2002.

10. Kurdi A, De Meyer GR and Martinet W: Potential therapeutic effects of mTORinhibition in atherosclerosis. Br J Clin Pharmacol 82: 1267-1279, 2016.

11. Zhao Y, Liu Y, Jing Z, Peng L, Jin P, Lin Y, Zhou Y, Yang L, Ren J, Xie Q and Jin X: N-oleoylethanolamide suppresses intimal hyperplasia after balloon injury in rats through AMPK/PPAR $\alpha$ pathway. Biochem Biophys Res Commun 496: 415-421, 2018.

12. Peng L, Huang X, Jin X, Jing Z, Yang L, Zhou Y, Ren J and Zhao Y: Wedelolactone, a plant coumarin, prevents vascular smooth muscle cell proliferation and injury-induced neointimal hyperplasia through Akt and AMPK signaling. Exp Gerontol 96: 73-81, 2017. 
13. Kim MK, Kim SH, Yu HS, Park HG, Kang UG, Ahn YM and Kim YS: The effect of clozapine on the AMPK-ACC-CPT1 pathway in the rat frontal cortex. Int J Neuropsychopharmacol 15 : 907-917, 2012

14. Kumar KG, Trevaskis JL, Lam DD, Sutton GM, Koza RA, Chouljenko VN, Kousoulas KG, Rogers PM, Kesterson RA, Thearle M, et al: Identification of adropin as a secreted factor linking dietary macronutrient intake with energy homeostasis and lipid metabolism. Cell Metab 8: 468-481, 2008

15. Wu L, Fang J, Yuan X, Xiong $C$ and Chen, L: Adropin reduces hypoxia/reoxygenation-induced myocardial injury via the reperfusion injury salvage kinase pathway. Exp Ther Med 18: 3307-3314, 2019

16. Altamimi TR, Gao S, Karwi QG, Fukushima A, Rawat S, Wagg CS, Zhang L and Lopaschuk GD: Adropin regulates cardiac energy metabolism and improves cardiac function and efficiency. Metabolism 98: 37-48, 2019.

17. Thapa D, Xie B, Zhang M, Stoner MW, Manning JR, Huckestein BR, Edmunds LR, Mullett SJ, McTiernan CF, Wendell SG, et al: Adropin treatment restores cardiac glucose oxidation in pre-diabetic obese mice. J Mol Cell Cardiol 129: 174-178, 2019.

18. Yosaee S, Soltani S, Sekhavati E and Jazayeri S: Adropin-a novel biomarker of heart disease: A systematic review article. Iran J Public Health 45: 1568-1576, 2016.

19. Zhao LP, You T, Chan SP, Chen JC and Xu WT: Adropin is associated with hyperhomocysteine and coronary atherosclerosis. Exp Ther Med 11: 1065-1070, 2016.

20. Sato K, Yamashita T, Shirai R, Shibata K, Okano T, Yamaguchi M, Mori Y, Hirano T and Watanabe T: Adropin contributes to anti-atherosclerosis by suppressing monocyte-endothelial cell adhesion and smooth muscle cell proliferation. Int J Mol Sci 19: 1293-1309, 2018

21. Mehran R, Dangas G, Abizaid AS, Mintz GS, Lansky AJ, Satler LF, Pichard AD, Kent KM, Stone GW and Leon MB Angiographic patterns of in-stent restenosis: Classification and implications for long-term outcome. Circulation 100: 1872-1878, 1999.

22. Mintz GS, Nissen SE, Anderson WD, Bailey SR, Erbel R, Fitzgerald PJ, Pinto FJ, Rosenfield K, Siegel RJ, Tuzcu EM and Yock PG: American college of cardiology clinical expert consensus document on standards for acquisition, measurement and reporting of intravascular ultrasound studies (IVUS). A report of the American college of cardiology task force on clinical expert consensus documents. J Am Coll Cardiol 37: 1478-1492,2001.

23. Ray JL, Leach R, Herbert JM and Benson M: Isolation of vascular smooth muscle cells from a single murine aorta. Methods Cell Sci 23: 185-188, 2001

24. Liao N, Shi Y, Zhang C, Zheng Y, Wang Y, Zhao B, Zeng Y, Liu X and Liu J: Antioxidants inhibit cell senescence and preserve stemness of adipose tissue-derived stem cells by reducing ROS generation during long-term in vitro expansion. Stem Cell Res Ther 10: 306, 2019.

25. Jojima T, Uchida K, Akimoto $K$, Tomotsune $T$, Yanagi $K$, Iijima T, Suzuki K, Kasai K and Aso Y: Liraglutide, a GLP-1 receptor agonist, inhibits vascular smooth muscle cell proliferation by enhancing AMP-activated protein kinase and cell cycle regulation, and delays atherosclerosis in ApoE deficient mice. Atherosclerosis 261: 44-51,2017.

26. National Research Council (US) Committee for the Update of the Guide for the Care and Use of Laboratory Animals: Guide for the care and use of laboratory animals, 8th edition. National Academic Press (US), Washington, DC, 2011.

27. Livak KJ and Schmittgen TD: Analysis of relative gene expression data using real-time quantitative PCR and the 2(-Delta Delta C(T)) method. Methods 25: 402-408, 2001

28. Ghoshal S, Stevens JR, Billon C, Girardet C, Sitaula S, Leon AS, Rao DC, Skinner JS, Rankinen T, Bouchard C, et al: Adropin: An endocrine link between the biological clock and cholesterol homeostasis. Mol Metab 8: 51-64, 2018.

29. Stevens JR, Kearney ML, St-Onge MP, Stanhope KL, Havel PJ, Kanaley JA, Thyfault JP, Weiss EP and Butler AA: Inverse association between carbohydrate consumption and plasma adropin concentrations in humans. Obesity (Silver Spring) 24: 1731-1740, 2016.

30. Zhu LH, Huang L, Zhang X, Zhang P, Zhang SM, Guan H, Zhang Y, Zhu XY, Tian S, Deng K and Li H: Mindin regulates vascular smooth muscle cell phenotype and prevents neointima formation. Clin Sci (Lond) 129: 129-145, 2015.
31. Ding Y, Zhang M, Zhang W, Lu Q, Cai Z, Song P, Okon IS Xiao L and Zou MH: AMP-activated protein kinase alpha 2 deletion induces VSMC phenotypic switching and reduces features of atherosclerotic plaque stability. Circ Res 119: 718-730, 2016.

32. Zhao Y, Shang F, Shi W, Zhang J, Zhang J, Liu X, Li B, Hu X and Wang L: Angiotensin II receptor type 1 antagonists modulate vascular smooth muscle cell proliferation and migration via AMPK/mTOR. Cardiology 143: 1-10, 2019.

33. Cuculi F, Bossard M, Zasada W, Moccetti F, Voskuil M, Wolfrum M, Malinowski KP, Toggweiler S and Kobza R: Performing percutaneous coronary interventions with predilatation using non-compliant balloons at high-pressure versus conventional semi-compliant balloons: Insights from two randomised studies using optical coherence tomography. Open heart 7: e001204, 2020.

34. Cassese S, De Luca G, Ribichini F, Cernigliaro C, Sansa M, Versaci F, Proietti I, Stankovic G, Stojkovic S, Fernandez-Pereira $\mathrm{C}$, et al: ORAl iMmunosuppressive therapy to prevent in-stent rEstenosiS (RAMSES) cooperation: A patient-level meta-analysis of randomized trials. Atherosclerosis 237: 410-417, 2014

35. Xie H, Yang J, Han Y, Zhu X and Fang Q: Inhibition of intimal hyperplasia via local delivery of vascular endothelial growth factor cDNA nanoparticles in a rabbit model of restenosis induced by abdominal aorta balloon injury. Exp Ther Med 10: 55-61, 2015.

36. Theodoropoulos K, Mennuni MG, Dangas GD, Meelu OA, Bansilal S, Baber U, Sartori S, Kovacic JC, Moreno PR, Sharma SK, et al: Resistant in-stent restenosis in the drug eluting stent era. Catheter Cardiovasc Interv 88: 777-785, 2016.

37. Jensen LO, Vikman S, Antonsen L, Kosonen P, Niemelä M, Christiansen EH, Kervinen K, Erglis A, Harnek J, Kumsars I, et al: Intravascular ultrasound assessment of minimum lumen area and intimal hyperplasia in in-stent restenosis after drug-eluting or bare-metal stent implantation. The nordic intravascular ultrasound study (NIVUS). Cardiovasc Revasc Med 18: 577-582, 2017.

38. Nakamura D, Yasumura K, Nakamura H, Matsuhiro $Y$, Yasumoto K, Tanaka A, Matsunaga-Lee Y, Yano M, Yamato M, Egami Y, et al: Different neoatherosclerosis patterns in drug-eluting- and bare-metal stent restenosis-optical coherence tomography study. Circ J 83: 313-319, 2019.

39. Ando H, Amano T, Takashima H, Harada K, Kitagawa K, Suzuki A, Kunimura A, Shimbo Y, Harada K, Yoshida T, et al: Differences in tissue characterization of restenotic neointima between sirolimus-eluting stent and bare-metal stent: integrated backscatter intravascular ultrasound analysis for in-stent restenosis. Eur Heart J Cardiovasc Imaging 14: 996-1001, 2013.

40. Zhao SG, Xu JJ, Tao ZH, Jin L, Liu Q, Zheng WY, Jiang LQ and Wang NF: $\mathrm{CHA}_{2} \mathrm{DS}_{2}$-Vasc score and $\mathrm{CHA}_{2} \mathrm{DS}_{2}$-Vasc-HS score are poor predictors of in-stent restenosis among patients with coronary drug-eluting stents. J Int Med Res 47: 2533-2544, 2019.

41. Umeda H, Kawai T, Misumida N, Ota T, Hayashi K, Iwase M, Izawa H, Sugino S, Shimizu T, Takeichi Y, et al: Impact of sirolimus-eluting stent fracture on 4-year clinical outcomes. Circ Cardiovasc Interv 4: 349-354, 2011.

42. Kubo S, Kadota K, Ozaki M, Ichinohe T, Eguchi H, Miyake K, Hyodo Y, Saito N, Otsuji H, Otsuru S, et al: Difference in clinical and angiographic characteristics of very late stent thrombosis between drug-eluting and bare-metal stent implantations. Circ J 77: 1453-1460, 2013

43. Conway C, Desany GJ, Bailey LR, Keating JH, Baker BL and Edelman ER: Fracture in drug-eluting stents increases focal intimal hyperplasia in the atherosclerosed rabbit iliac artery. Catheter Cardiovasc Interv 93: 278-285, 2019.

44. Bochaton-Piallat ML and Gabbiani G: Modulation of smooth muscle cell proliferation and migration: Role of smooth muscle cell heterogeneity. Atherosclerosis: Diet and Drugs. Springer, Berlin, Heidelberg, pp645-663, 2005.

45. Lovren F, Pan Y, Quan A, Singh KK, Shukla PC, Gupta M, Al-Omran M, Teoh H and Verma S: Adropin is a novel regulator of endothelial function. Circulation 122 (Suppl 11): S185-S192, 2010.

46. Herzig S and Shaw RJ: AMPK: Guardian of metabolism and mitochondrial homeostasis. Nat Rev Mol Cell Biol 19: 121-135, 2018.

47. Stone JD, Narine A, Shaver PR, Fox JC, Vuncannon JR and Tulis DA: AMP-activated protein kinase inhibits vascular smooth muscle cell proliferation and migration and vascular remodeling following injury. Am J Physiol Heart Circ Physiol 304: H369-H381, 2013. 
48. Osman I and Segar L: Pioglitazone, a PPAR $\gamma$ agonist, attenuates PDGF-induced vascular smooth muscle cell proliferation through AMPK-dependent and AMPK-independent inhibition of mTOR/p70S6K and ERK signaling. Biochem Pharmacol 101: 54-70, 2016.

49. Nagata D, Takeda R, Sata M, Satonaka H, Suzuki E, Nagano T and Hirata Y: AMP-activated protein kinase inhibits angiotensin II-stimulated vascular smooth muscle cell proliferation. Circulation 110: 444-451, 2004.

50. Igata M, Motoshima H, Tsuruzoe K, Kojima K, Matsumura T, Kondo T, Taguchi T, Nakamaru K, Yano M, Kukidome D, et al: Adenosine monophosphate-activated protein kinase suppresses vascular smooth muscle cell proliferation through the inhibition of cell cycle progression. Circ Res 97: 837-844, 2005.

51. Peyton KJ, Yu Y, Yates B, Shebib AR, Liu XM, Wang H and Durante W: Compound C inhibits vascular smooth muscle cell proliferation and migration in an AMP-activated protein kinase-independent fashion. J Pharmacol Exp Ther 338: 476-484, 2011.

52. Song P, Wang S, He C, Wang S, Liang B, Viollet B and Zou MH: AMPKalpha2 deletion exacerbates neointima formation by upregulating Skp2 in vascular smooth muscle cells. Circ Res 109: $1230-1239,2011$.

53. Kim SY, Jeoung NH, Oh CJ, Choi YK, Lee HJ, Kim HJ, Kim JY, Hwang JH, Tadi S, Yim YH, et al: Activation of NAD $(\mathrm{P})$ $\mathrm{H}$ :Quinone oxidoreductase 1 prevents arterial restenosis by suppressing vascular smooth muscle cell proliferation. Circ Res 104: 842-850, 2009.

54. Smith BK and Steinberg GR: AMP-activated protein kinase, fatty acid metabolism, and insulin sensitivity. Curr Opin Clin Nutr Metab Care 20: 248-253, 2017.

55. Bonnefont JP, Djouadi F, Prip-Buus C, Gobin S, Munnich A and Bastin J: Carnitine palmitoyltransferases 1 and 2: Biochemical, molecular and medical aspects. Mol Aspects Med 25: 495-520, 2004.
56. Ferdinandusse S, Denis S, Van Roermund CW, Wanders RJ and Dacremont G: Identification of the peroxisomal beta-oxidation enzymes involved in the degradation of long-chain dicarboxylic acids. J Lipid Res 45: 1104-1111, 2004.

57. Lochner M, Berod L and Sparwasser T: Fatty acid metabolism in the regulation of $\mathrm{T}$ cell function. Trends Immunol 36: 81-91, 2015

58. Gao S, McMillan RP, Jacas J, Zhu Q, Li X, Kumar GK, Casals N, Hegardt FG, Robbins PD, Lopaschuk GD, et al: Regulation of substrate oxidation preferences in muscle by the peptide hormone adropin. Diabetes 63: 3242-3252, 2014.

59. Thapa D, Stoner MW,Zhang M, Xie B, Manning JR, Guimaraes D, Shiva S, Jurczak MJ and Scott I: Adropin regulates pyruvate dehydrogenase in cardiac cells via a novel GPCR-MAPK-PDK4 signaling pathway. Redox Biol 18: 25-32, 2018.

60. Gobin S, Thuillier L, Jogl G, Faye A, Tong L, Chi M, Bonnefont JP, Girard J and. Prip-Buus C: Functional and structural basis of carnitine palmitoyltransferase 1A deficiency. J Biol Chem 278: 50428-50434, 2003

61. Oaxaca-Castillo D, Andreoletti P, Vluggens A, Yu S Van Veldhoven PP, Reddy JK and Cherkaoui-Malki M: Biochemical characterization of two functional human liver acyl-CoA oxidase isoforms $1 \mathrm{a}$ and $1 \mathrm{~b}$ encoded by a single gene. Biochem Biophys Res Commun 360: 314-319, 2007.

62. Wu L, Fang J, Chen L, Zhao Z, Luo Y, Lin C and Fan L: Low serum adropin is associated with coronary atherosclerosis in type 2 diabetic and non-diabetic patients. Clin Chem Lab Med 52: 751-758, 2014.

This work is licensed under a Creative Commons Attribution-NonCommercial-NoDerivatives 4.0 International (CC BY-NC-ND 4.0) License. 